\title{
Silicophosphate/silicophosphite hybrid materials prepared by solventless ethanol condensation
}

\author{
Yomei TOKUDA, ${ }^{\dagger}$ Yusuke TANAKA, Masahide TAKAHASHI, Rie IHARA and Toshinobu YOKO
}

Institute for Chemical Research, Kyoto University, Gokasho, Uji, Kyoto 611-0011

\begin{abstract}
We have developed organic-inorganic silicophosphate and silicophenylphosphite hybrid materials by means of alcohol condensation between organically modified alkoxysilane and anhydrous phosphoric or phosphonic acid under a solventless, catalystfree, low-temperature, one-pot condition. The hybrid exhibits a low-melting property and is chemically more durable than that prepared by using a nonaqueous acid-base reaction between anhydrous phosphoric acid and organically modified chlorosilane. ${ }^{29} \mathrm{Si}$ and ${ }^{31} \mathrm{P}$ NMR analyses have shown that the alcohol condensation yield was around $80 \%$. Quantum chemical calculations have also performed in order to clarify the chemical durability improvement of the hybrids.
\end{abstract}

(C2009 The Ceramic Society of Japan. All rights reserved.

Key-words : Silicophosphate, Organic-inorganic hybrid, Low-melting, NMR, Quantum chemical calculation

[Received March 24, 2009; Accepted June 18, 2009]

\section{Introduction}

Organic-inorganic hybrid materials are potential candidates for use in the fabrication of electronic and photonic devices with high functionality because these materials can be processed easily and have a high solubility of functional molecules. ${ }^{1)}$ Such materials are frequently prepared by using a sol-gel method because of their composition selectivity and low-temperature processibility. However, the sol-gel process is sometimes complicated, and it is difficult to obtain monolithic material because of crack formation during solvent evaporation. ${ }^{2)}$

Recently, an organic-inorganic silicophosphate hybrid has been obtained under a solventless, catalyst-free, low-temperature, onepot condition ${ }^{3)-6)}$ by using orthophosphoric acid and organically modified chlorosilane. The following acid-base reaction (metathesis) took place: $\mathrm{Si}-\mathrm{Cl}+\mathrm{P}-\mathrm{OH} \rightarrow \mathrm{Si}-\mathrm{O}-\mathrm{P}+\mathrm{HCl} \uparrow$. Here the reaction formula omitted the groups which do not participate in the reaction: $\mathrm{Me}_{2} \mathrm{SiCl}_{2}+\mathrm{H}_{3} \mathrm{PO}_{4} \rightarrow \mathrm{Me}_{2} \mathrm{ClSiOP}(\mathrm{OH})_{2} \mathrm{O}+\mathrm{HCl} \uparrow$ is abbreviated as $\mathrm{Si}-\mathrm{Cl}+\mathrm{P}-\mathrm{OH} \rightarrow \mathrm{Si}-\mathrm{O}-\mathrm{P}+\mathrm{HCl} \uparrow$. The starting materials were mixed and heat-treated at less than $300^{\circ} \mathrm{C}$. The resultant viscous liquid was cooled down to an ambient temperature, producing a transparent monolithic hybrid material that contained an almost complete alternating polymer consisting of silicate and phosphate units and a high homogeneity in an intermolecular scale. The crack-free monolithic hybrid material was easily obtained because of the absence of solvent evaporation.

One can easily introduce organic dyes into the abovementioned hybrid material as it melts at temperatures less than $100^{\circ} \mathrm{C}$ and possesses various organic groups. ${ }^{7)}$ Additionally, rare earth ions and Au nanoparticles can be easily dispersed in this hybrid material because the present material has copolymer structure consisting of silicate and phosphate units. ${ }^{8)}$ This high solubility of both the organic and the inorganic functional centers is one of the advantages of the optical host material application.

Another advantage of this organic-inorganic hybrid material is related to the low-temperature processibility of the material

Corresponding author: Y. Tokuda; E-mail: tokuda@noncry.kuicr. kyoto-u.ac.jp because the melting temperature of the material is less than $100^{\circ} \mathrm{C}$, the material can be used in a hot-emboss technique or photothermal fabrication in order to obtain photonic devices. ${ }^{9)}$ We have also fabricated a photograting structure with a submicron resolution in the silicophosphate hybrid.

The abovementioned reaction produces $\mathrm{HCl}$ gas, which is both toxic and caustic. Additionally, the residual $\mathrm{HCl}$ gas in the hybrid material may act as a catalyst for the hydrolysis of $\mathrm{Si}-\mathrm{O}-\mathrm{P}$ bonding, resulting in low durability. Thus, the silicophosphate hybrid prepared by the acid-base reaction is not durable. ${ }^{10)-13)}$

In this study, we will develop another class of low-melting silicophosphate hybrid formation reaction that is based on solventless alcohol condensation without $\mathrm{HCl}$ production: $\mathrm{Si}-\mathrm{OEt}+$ $\mathrm{P}-\mathrm{OH} \rightarrow \mathrm{Si}-\mathrm{O}-\mathrm{P}+\mathrm{EtOH} \uparrow{ }^{14)}$ Although this type of reaction is known as a nonhydrolytic sol-gel reaction, there are few reports on the silicophosphate network formation. ${ }^{15)}$ Therefore, the structure analyses have also been carried out using ${ }^{29} \mathrm{Si}$ and ${ }^{31} \mathrm{P}$ nuclear magnetic resonance (NMR). The thermal property and the chemical durability of the hybrid material have also been investigated. Quantum chemical calculations have been performed in order to investigate the hydrolysis of the $\mathrm{Si}-\mathrm{O}-\mathrm{P}$ bonding in the silicophosphate hybrid.

\section{Experimental}

2.1 Preparation of organically modified silicophosphate and silicophenylphosphite hybrid

Anhydrous orthophosphoric acid $\left(\mathrm{H}_{3} \mathrm{PO}_{4}\right)$ (Aldrich Co., Ltd.) and phenylphosphonic acid $\left(\mathrm{PhH}_{2} \mathrm{PO}_{3}\right)$ (Aldrich Co., Ltd.) were used as the phosphoric and the phosphonic acids, respectively. Diphenyldiethoxysilane $\left(\mathrm{Ph}_{2} \mathrm{Si}(\mathrm{OEt})_{2}\right)$ (Shin-Etsu Chemical Co., Ltd.) was used as the organosilane. Diphenyldichlorosilane $\left(\mathrm{Ph}_{2} \mathrm{SiCl}_{2}\right)$ (Shin-Etsu Chemical Co., Ltd.) was also used for the sake of comparison. The compositions of the starting materials were $\mathrm{H}_{3} \mathrm{PO}_{4}: \mathrm{Ph}_{2} \mathrm{Si} X_{2}=x:(1-x)(x=0,0.6)$ and $\mathrm{Ph}_{2} \mathrm{H}_{2} \mathrm{PO}_{3}$ : $\mathrm{Ph}_{2} \mathrm{SiX}_{2}=y:(1-y)(y=0,0.5)(X=\mathrm{Cl}$ or $\mathrm{OEt})$, as shown in Table 1. The samples made from $\mathrm{H}_{3} \mathrm{PO}_{4}$ and $\mathrm{Ph}_{2} \mathrm{Si}(\mathrm{OEt})_{2}$ were designated as silicophosphate hybrid $\mathrm{A}$, while silicophosphate hybrid $\mathrm{B}$ was made from $\mathrm{H}_{3} \mathrm{PO}_{4}$ and $\mathrm{Ph}_{2} \mathrm{SiCl}_{2}$. Silicophenylphosphite hybrids $\mathrm{C}$ and $\mathrm{D}$ were made from phenylpho- 
Table 1. Compositions of the Starting Reagents. The Values are Listed in mol\% Unit

\begin{tabular}{ccccc}
\hline & $\mathrm{Ph}_{2} \mathrm{Si}(\mathrm{OEt})_{2}$ & $\mathrm{Ph}_{2} \mathrm{SiCl}_{2}$ & $\mathrm{H}_{3} \mathrm{PO}_{4}$ & $\mathrm{PhH}_{2} \mathrm{PO}_{3}$ \\
\hline A & 60 & - & 40 & - \\
$\mathrm{B}$ & - & 60 & 40 & - \\
$\mathrm{C}$ & 50 & - & - & 50 \\
$\mathrm{D}$ & - & 50 & - & 50 \\
\hline
\end{tabular}

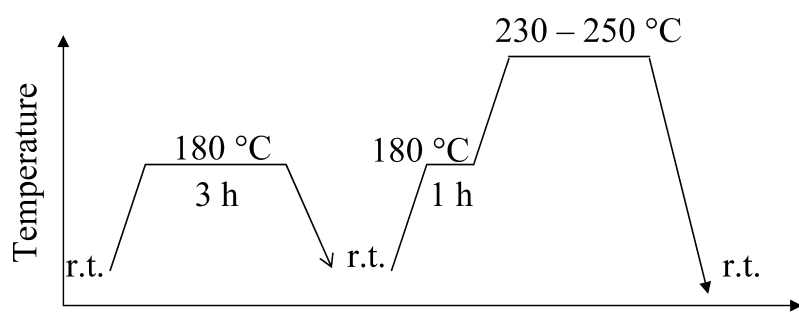

Time / h

Fig. 1. Preparation scheme of organic-inorganic hybrid material from $\mathrm{H}_{3} \mathrm{PO}_{4}, \mathrm{PhH}_{2} \mathrm{PO}_{3}$ and $\mathrm{Ph}_{2} \mathrm{Si}_{2}(X=\mathrm{Cl}, \mathrm{OEt})$.

sphonic acid and $\mathrm{Ph}_{2} \mathrm{Si}_{2}(X=\mathrm{OEt}$ for $\mathrm{C}$ and $X=\mathrm{Cl}$ for $\mathrm{D})$. The compositions of all the starting reagents were stoichiometric.

A mixture of the starting reagents was stirred and heat-treated at $180^{\circ} \mathrm{C}$ for $3 \mathrm{~h}$, and quenched to room temperature. The resulting product was designated as the precursor. The precursor was melted again at $180^{\circ} \mathrm{C}$ for $1 \mathrm{~h}$ and $230-250^{\circ} \mathrm{C}$ for $3 \mathrm{~h}$. Subsequently, the melt was quenched to room temperature. Figure 1 shows the preparation scheme. The preparation process was carried out in an $\mathrm{N}_{2}$ atmosphere.

\subsection{Characterization of organically modified silico- phosphate}

The softening temperature, $T_{\mathrm{s}}$, of the samples was measured by a thermal mechanical analysis using TMA 8310 (Rigaku Co.) under $1 \mathrm{~g}$ loading at a heating rate of $10 \mathrm{~K} / \mathrm{min}$.

The hybrid samples were prepared in glass cups $(50 \mathrm{~mL})$ in order to maintain a constant surface area exposed to the surrounding atmosphere at $8.2 \mathrm{~cm}^{2}$. The durability of the materials was determined by the weight gain in saturated water vapor at $25^{\circ} \mathrm{C}$. The hydrolysis of the hybrid provides the weight gain due to the water uptake: $\mathrm{Si}-\mathrm{O}-\mathrm{P}+\mathrm{H}_{2} \mathrm{O} \rightarrow \mathrm{Si}-\mathrm{OH}+\mathrm{P}-\mathrm{OH}$. A smaller weight gain corresponds to a higher durability.

The structure analyses were also performed using ${ }^{29} \mathrm{Si}$ and ${ }^{31} \mathrm{P}$ magic angle spinning (MAS) NMR. The spinning rate for MAS was set to $3 \mathrm{kHz}$ and $11-13 \mathrm{kHz}$ for ${ }^{29} \mathrm{Si}$ and ${ }^{31} \mathrm{P}$, respectively. In order to assign the peak precisely, the static ${ }^{29} \mathrm{Si} \mathrm{NMR} \mathrm{spectra}$ were also obtained for the precursors $\mathrm{A}, \mathrm{B}$, and $\mathrm{C}$ dissolved in ethanol. The chemical shifts were presented in ppm with respect to tetramethylsilane for ${ }^{29} \mathrm{Si}(0 \mathrm{ppm})$ or phosphoric acid for ${ }^{31} \mathrm{P}$ (0 ppm).

\subsection{Quantum chemical calculations}

In order to investigate the hydrolysis behavior of the Si-O-P bonding, the quantum chemical calculations were carried out on the model clusters as shown in Fig. 2 using the Gaussian 03 program. ${ }^{16)}$ Models I and II simulated the hydrolysis in the silicophosphate and silicophenylphosphite hybrids, respectively. In order to reduce the computation time, we considered the methyl

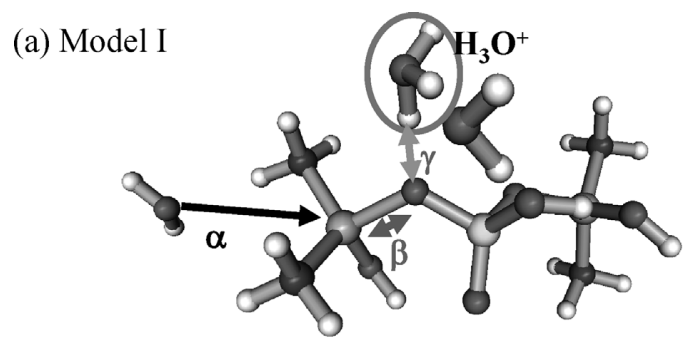

(b) Model II

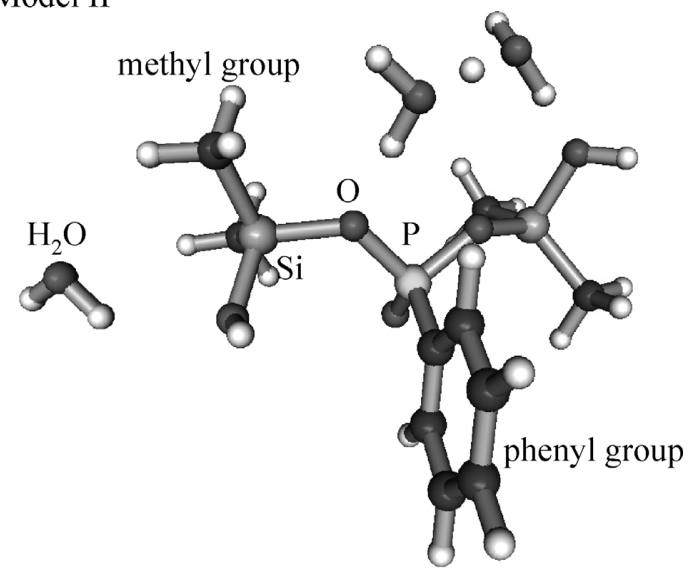

Fig. 2. Transition state structures of the hydrolysis: (a) silicophophate hybrid, (b) silicophenylphosphite hybrid. The geometry optimizations were performed at B3LYP/6-31G* level. The distance $\alpha, \beta$ and $\gamma$ corresponds to the distance between $\mathrm{O}$ in water and $\mathrm{Si}$, the $\mathrm{Si}-\mathrm{O}$ length in the $\mathrm{Si}-\mathrm{O}-\mathrm{P}$ bonding, and the distance between $\mathrm{O}$ in $\mathrm{Si}-\mathrm{O}-\mathrm{P}$ bonding and $\mathrm{H}$ in $\mathrm{H}_{3} \mathrm{O}^{+}$, respectively. We also calculated the total energy for the constant distance $\beta$ in order to investigate the activation energy of hydrolysis.

groups on the Si atom instead of the phenyl groups for the simulations. Both the models had an oxonium ion as the catalyst and a hydrolyzing $\mathrm{H}_{2} \mathrm{O}$ molecule. Additionally, the models without the oxonium ion and $\mathrm{H}_{2} \mathrm{O}$ were also calculated. The geometry optimization and the Mulliken population analysis were carried out at B3LYP/6-31G* level with a constant distance between $\mathrm{Si}$ and the hydrolyzing $\mathrm{H}_{2} \mathrm{O}$. The transition state structures were also obtained by IRC calculation at the B3LYP/6-31G* level. The single point energy calculations were performed at the MP2/ 6-311+G** level. All the calculations were performed by using the supercomputer Origin 3800 at the Supercomputer Laboratory, Institute for Chemical Research, Kyoto University.

\section{Results}

The precursors were highly viscous and homogeneous transparent liquids. The final products were transparent, homogeneous, colorless, and crack-free solids.

The TMA curves of the products showed that $T_{\mathrm{s}}$ ranged from $50^{\circ} \mathrm{C}$ to $130^{\circ} \mathrm{C}\left(\right.$ Fig. 3). The $T_{\mathrm{s}}$ values of the samples were found to be in the following order: $\mathrm{B}>\mathrm{A}>\mathrm{D}>\mathrm{C}$. Phosphoric acid provided a sample with higher $T_{\mathrm{s}}$ than phenylphosphonic acid did; $\mathrm{A}$ and $\mathrm{B}$ exhibited higher $T_{\mathrm{s}}$ than $\mathrm{C}$ and $\mathrm{D}$ did. It was also found that the acid-base reaction provided samples with higher $T_{\mathrm{s}}$ than the alcohol condensation reaction did; B and D exhibited higher $T_{\mathrm{s}}$ than A and $\mathrm{C}$ did, respectively.

In contrast to $T_{\mathrm{s}}$, the durability of the samples was found to be in the following order: $\mathrm{C}>\mathrm{D}>\mathrm{A}>\mathrm{B}$ (Fig. 4). The samples prepared by using solventless ethanol condensation (samples A and 


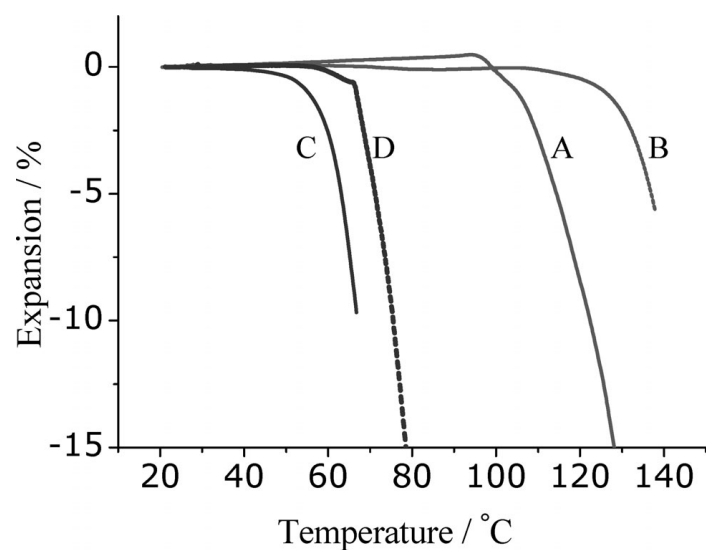

Fig. 3. TMA curves of the silicophosphate and silicophenylphosphite hybrids.

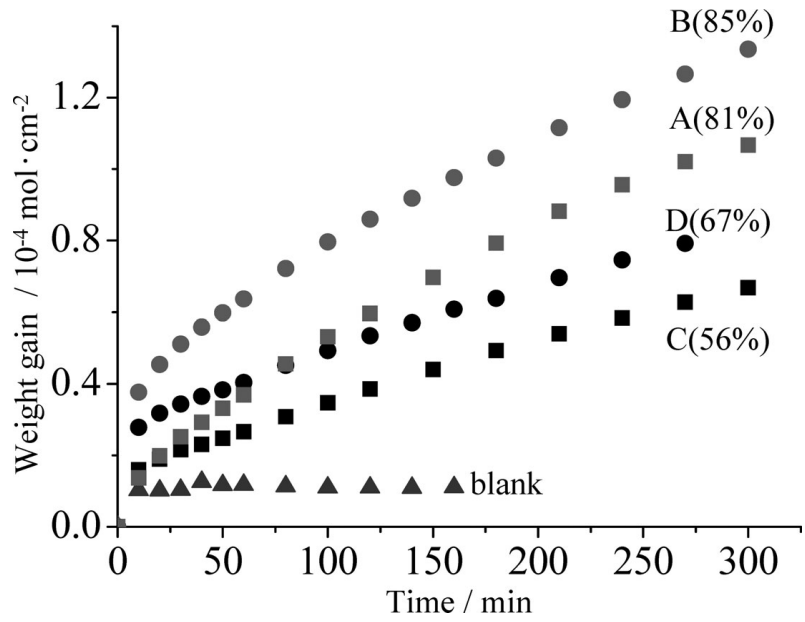

Fig. 4. Weight gain in saturated water vapor at $25^{\circ} \mathrm{C}$. The inset values are referred to the yields of $\mathrm{P}-\mathrm{O}-\mathrm{Si}$ bonding formation defined by the Eq. (1) in the article.

C) were chemically more durable than those prepared by using a nonaqueous acid-base reaction (samples $\mathrm{B}$ and $\mathrm{D}$ ). We also found that the silicophenylphosphite hybrids $\mathrm{C}$ and $\mathrm{D}$ were more durable than silicophosphate hybrids $\mathrm{A}$ and $\mathrm{B}$, respectively. The appearance of the hybrid $\mathrm{C}$ after exposed to water vapor was transparent, hybrids D, A translucent, and hybrid B opaque.

The ${ }^{31} \mathrm{P}$ MAS NMR spectra of the samples are shown in Fig. 5. For samples $A$ and $B$, three peaks were observed around -11 , -23 , and $-35 \mathrm{ppm}$, while for samples $\mathrm{C}$ and $\mathrm{D}$, the peaks were observed around 15,8 , and $-3 \mathrm{ppm}$. The areas obtained by a gaussian deconvolution are listed in Table 2.

In contrast to ${ }^{31} \mathrm{P}$ NMR spectra, the ${ }^{29} \mathrm{Si}$ MAS NMR spectra of all the samples exhibited a featureless peak only at $-40 \mathrm{ppm}$, as shown in Fig. 6(d). The ${ }^{29} \mathrm{Si}$ chemical shifts of the precursors $\mathrm{A}, \mathrm{B}$ and $\mathrm{C}$ dissolved in ethanol were $-32,-37,-39,-43$ and -46 ppm, as shown in Fig. 6(a)-(c).

The relative total energies of models I and II calculated by using the quantum chemical calculations were given in Fig. 7. The relative energy (closed circles), the distance between $\mathrm{Si}$ and $\mathrm{H}_{2} \mathrm{O}$ (distance $\gamma$ in Fig. 2, open squares), and that between silicon and oxygen (distance $\beta$, open triangles) for (a) model I and (b) model II were plotted against the distance between the Si$\mathrm{O}-\mathrm{P}$ bonding. This result indicated that when the distance

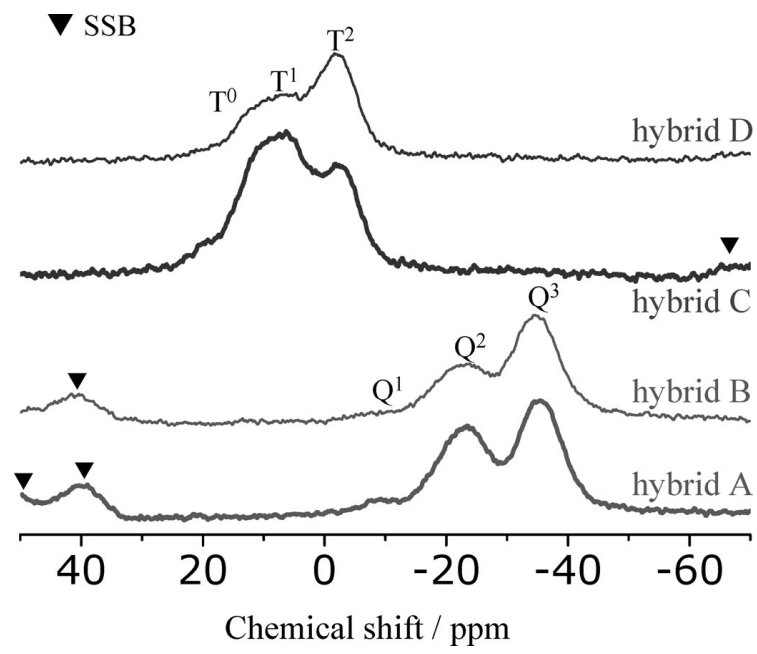

Fig. 5. $\quad{ }^{31} \mathrm{P}$ MAS NMR spectra of the hybrid materials. $Q^{n}$ and $T^{n}$ are refered to $\mathrm{P}$ with $n$ bridging oxygens and (4-n) non-bridging oxygens and that with $n$ bridging oxygens and $(3-n)$ non-bridging oxygens, respectively.

Table 2. Areas of $Q^{n}$ and $T^{n}$ units calculated from ${ }^{31} \mathrm{P}$ MAS NMR Spectra. The Yields of the $\mathrm{P}-\mathrm{O}-\mathrm{Si}$ Bonding Formation were also Calculated as $\mathrm{N}(\mathrm{P}-\mathrm{OSi}) /(\mathrm{N}(\mathrm{P}-\mathrm{OH})+\mathrm{N}(\mathrm{P}-\mathrm{Si})) \times 100$

\begin{tabular}{rrrrcc}
\hline $\mathrm{n}$ & 0 & 1 & 2 & 3 & yield \\
\hline A & 0 & 7 & 41 & 51 & 81 \\
B & 0 & 9 & 29 & 63 & 85 \\
C & 20 & 48 & 32 & - & 56 \\
D & 11 & 44 & 45 & - & 67 \\
\hline
\end{tabular}

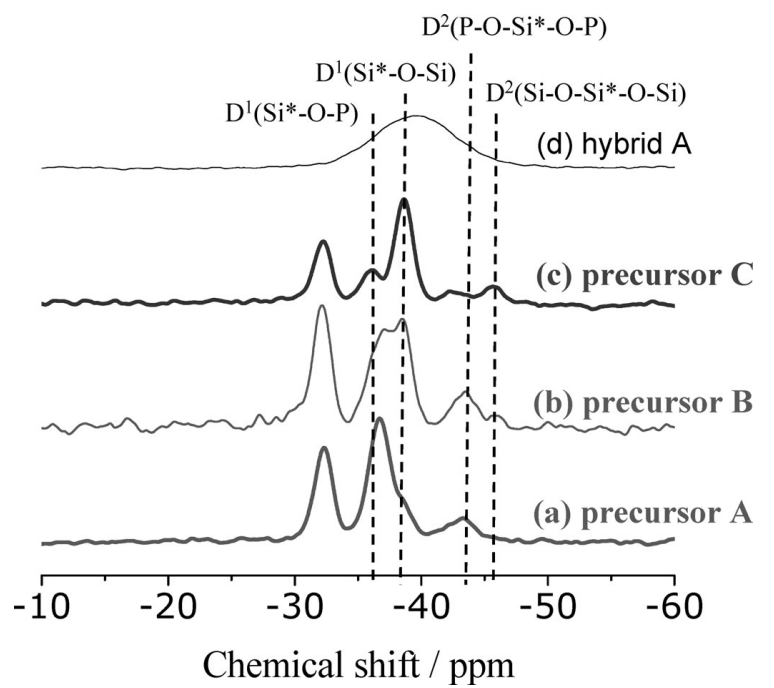

Fig. 6. ${ }^{29} \mathrm{Si}$ NMR spectra of (a) precursor A, (b) precursor B, (c) precursor C, and (d) ${ }^{29}$ Si MAS NMR spectra of hybrid A. The asterisks on the atomic symbols refer to the nuclei responsible for the chemical shift.

between $\mathrm{Si}$ and $\mathrm{H}_{2} \mathrm{O}$ was decreased, the $\mathrm{Si}-\mathrm{O}$ distance in $\mathrm{Si}-\mathrm{O}-$ $\mathrm{P}$ bonding increased and the distance between the oxygen in $\mathrm{Si}-$ $\mathrm{O}-\mathrm{P}$ bonding and the hydrogen in $\mathrm{H}_{3} \mathrm{O}^{+}$decreased to $1.0 \AA$. As the total energies of model I first increased and then decreased with decreasing the distance $\alpha$, the IRC calculation was per- 

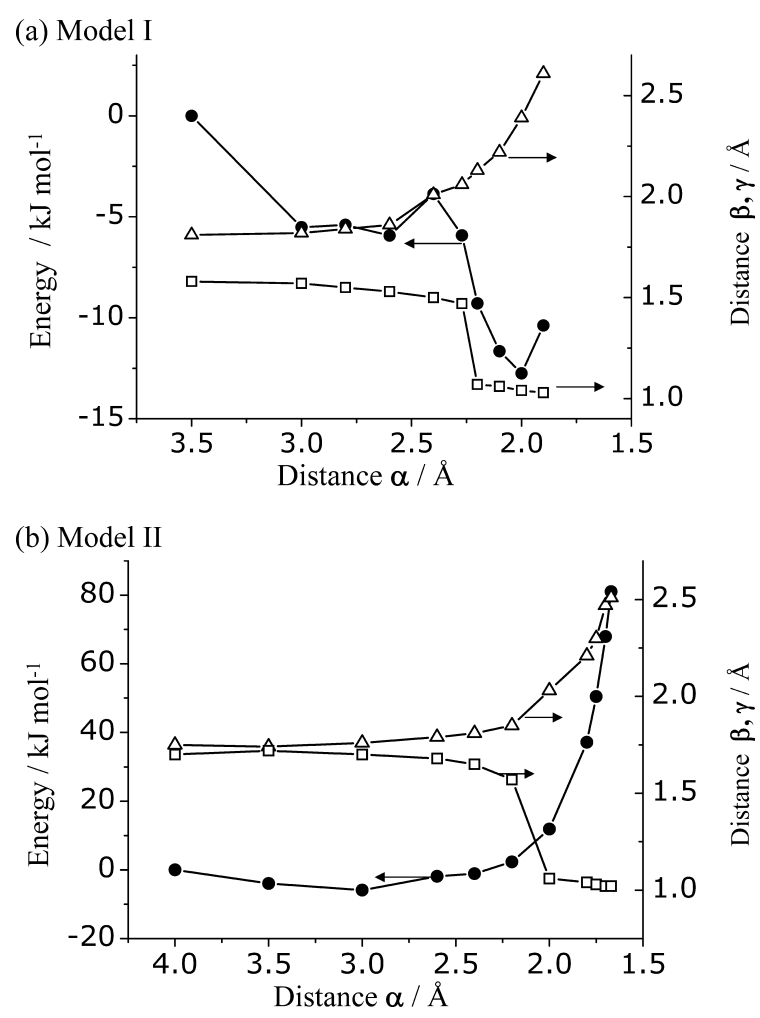

Fig. 7. Relative total energy ( $)$, the distance $\beta(\triangle)$, and the distance $\gamma$ ( $\square$ )for (a) model I and (b) model II plotted against the distance $\alpha$ between $\mathrm{Si}-\mathrm{O}-\mathrm{P}$ bonding.

formed to obtain the transition state structure as shown in Fig. 2. This calculation succeeded and provided an activation energy of $1.9 \mathrm{~kJ} / \mathrm{mol}$. On the other hand, the model II provides no transition structure, as its total energy increased monotonously and IRC calculation failed. The Mulliken charges of the oxygen in $\mathrm{Si}-$ O-P bonding in the model I without the oxonium ion and $\mathrm{H}_{2} \mathrm{O}$ were also calculated as -0.54 , and -0.38 in the model II.

\section{Discussion}

The ${ }^{31} \mathrm{P}$ MAS NMR peaks for samples $\mathrm{A}$ and $\mathrm{B}$ around -11 , -23 , and $-35 \mathrm{ppm}$ were assigned to $\mathrm{P}$ in $\mathrm{PO}\left(\mathrm{OSiPh}_{2}\right)(\mathrm{OH})_{2}$, $\mathrm{PO}\left(\mathrm{OSiPh}_{2}\right)_{2} \mathrm{OH}$, and $\mathrm{PO}\left(\mathrm{OSiPh}_{2}\right)_{3}$, respectively; the $\mathrm{P}$ units were referred to as $Q^{1}, Q^{2}$, and $Q^{3}$ because the ${ }^{31} \mathrm{P}$ chemical shift in the $\mathrm{P}-\mathrm{O}-\mathrm{Si}$ bond provided a higher field shift than that in the $\mathrm{P}-\mathrm{OH}$ bond. ${ }^{12)}$ Here, $Q^{n}$ refers to $\mathrm{P}$ with $\mathrm{n}$ bridging oxygens and (4-n) nonbridging oxygens. The peaks for samples $\mathrm{C}$ and $\mathrm{D}$ around 15, 8, and $-3 \mathrm{ppm}$ were also assigned to ${ }^{31} \mathrm{P}$ in $\mathrm{PhH}_{2} \mathrm{PO}_{3}$, $\mathrm{PhPO}\left(\mathrm{OSiPh}_{2}\right)(\mathrm{OH})$, and $\mathrm{PhPO}\left(\mathrm{OSiPh}_{2}\right)_{2}$, respectively; ${ }^{11)}$ these $\mathrm{P}$ units were referred to as $T^{0}, T^{1}$, and $T^{2}$, where $T^{n}$ refers to $\mathrm{P}$ with $n$ bridging oxygens and $(3-n)$ nonbridging oxygens. Table 2 lists the ratios of each structure unit and yield of $\mathrm{P}-\mathrm{O}-\mathrm{Si}$ bond formation calculated as follows:

$$
\frac{\mathrm{N}(\mathrm{P}-\mathrm{OSi})}{\mathrm{N}(\mathrm{P}-\mathrm{OH})+\mathrm{N}(\mathrm{P}-\mathrm{OSi})} \times 100(\%),
$$

where $\mathrm{N}(\mathrm{P}-\mathrm{O} X)$ indicates the number of $\mathrm{P}$ atoms with $\mathrm{P}-\mathrm{O} X$ bonding $(X=\mathrm{Si}$ or $\mathrm{H})$. The ability to form a $\mathrm{P}-\mathrm{O}-\mathrm{Si}$ bond was found to be in the following order: $\mathrm{B}>\mathrm{A}>\mathrm{D}>\mathrm{C}$. The fact that the yields for the silicophosphate hybrids (samples A or B) were larger than those of the silicophenylphosphite hybrids (samples $\mathrm{C}$ or D) indicated that the use of $\mathrm{H}_{3} \mathrm{PO}_{4}$ as the starting reagent resulted in a higher yield of the $\mathrm{P}-\mathrm{O}-\mathrm{Si}$ bond than that of $\mathrm{PhH}_{2} \mathrm{PO}_{3}$ did. Additionally, the yield for solventless alcohol condensation (samples A and C) was slightly lower than that of the nonaqueous acid-base reaction (samples $\mathrm{B}$ and $\mathrm{D}$ ).

As mentioned in results section, the peak deconvolution is impossible for the ${ }^{29} \mathrm{Si}$ MAS NMR spectra because the peak at $-40 \mathrm{ppm}$ is featureless. Therefore, peak assignment was performed using the static NMR spectra of liquid samples because liquid NMR provided sharp spectra, although they did not provide quantitative information. Obviously the peaks at -37 and $-43 \mathrm{ppm}$ in Figs. 6 were also assigned to $\mathrm{Si}$ in $\mathrm{Ph}_{2} \mathrm{Si}(\mathrm{OEt})\left(\mathrm{OP}(\mathrm{OH})_{2}\right)$, and $\mathrm{Ph}_{2} \mathrm{Si}\left(\mathrm{OP}(\mathrm{OH})_{2}\right)_{2}$, respectively; these $\mathrm{Si}$ units were referred to as $\mathrm{D}^{1}\left(\mathrm{Si}^{*}-\mathrm{O}-\mathrm{P}\right)$ and $\mathrm{D}^{2}\left(\mathrm{P}-\mathrm{O}-\mathrm{Si}^{*}-\mathrm{O}-\mathrm{P}\right) .{ }^{11), 12}$ Here, the asterisk refers to the nucleus that was responsible for the chemical shift. The peaks at $-32,-39$, and $-46 \mathrm{ppm}$ in Fig. 6(a)-(c) were assigned to $\mathrm{Si}$ in $\mathrm{Ph}_{2} \mathrm{Si}(\mathrm{OEt})_{2}, \mathrm{Ph}_{2} \mathrm{Si}(\mathrm{OEt})\left(\mathrm{OSiPh}_{2}(\mathrm{OH})\right)$, and $\mathrm{Ph}_{2} \mathrm{Si}\left(\mathrm{OSiPh}_{2}(\mathrm{OH})\right)_{2}$, respectively; ${ }^{17), 18)}$ these $\mathrm{Si}$ units were designated as $\mathrm{D}^{0}, \mathrm{D}^{1}\left(\mathrm{Si}^{*}-\mathrm{O}-\mathrm{Si}\right)$, and $\mathrm{D}^{2}\left(\mathrm{Si}-\mathrm{O}-\mathrm{Si}^{*}-\mathrm{O}-\mathrm{Si}\right)$. On the basis of this assignment, the featureless peak at $-40 \mathrm{ppm}$ observed in the hybrids was mainly attributed to the $\mathrm{Si}$ in the $\mathrm{D}^{1}\left(\mathrm{Si}^{*}-\mathrm{O}-\mathrm{P}\right), \mathrm{D}^{1}\left(\mathrm{Si}^{*}-\mathrm{O}-\mathrm{Si}\right)$, and $\mathrm{D}^{2}\left(\mathrm{P}-\mathrm{O}-\mathrm{Si}^{*}-\mathrm{O}-\mathrm{P}\right)$ units. Ideally, there should be no $\mathrm{Si}-\mathrm{O}-\mathrm{Si}$ bonding when only alcohol condensation occurs. However, the system including phosphoric or phosphonic acid contained a little amount of water as impurity or the self-condensation reaction of the acids produced water, $2 \mathrm{POH} \rightarrow \mathrm{P}-\mathrm{O}-\mathrm{P}+\mathrm{H}_{2} \mathrm{O}$. This water hydrolyzed the diphenyldiethoxysilane with the help of the phosphoric or phosphonic acid. Hence, $\mathrm{Si}-\mathrm{O}-\mathrm{Si}$ bonding was present in the products. As mentioned in the preceding discussion on ${ }^{31} \mathrm{P}$ MAS NMR, Si-O-P bonds were mainly formed by the ethanol condensation reaction. Additionally, Si-O-Si bond was formed as a by-product.

In the case of the acid-base reaction, the formation of the byproduct was negligible. ${ }^{11), 13)}$ The present authors have proposed the condensation mechanism as follows, ${ }^{11), 12)}$

$$
\begin{aligned}
& 2 \mathrm{H}_{3} \mathrm{PO}_{4} \rightarrow \mathrm{H}_{4} \mathrm{PO}_{4}^{+}+\mathrm{H}_{2} \mathrm{PO}_{4}^{-} \\
& \mathrm{R}_{2} \mathrm{Si} X_{2}+\mathrm{H}_{2} \mathrm{PO}_{4}^{-} \rightarrow \mathrm{R}_{2} X \mathrm{Si}-\mathrm{O}-\mathrm{PO}_{3} \mathrm{H}_{2}+X^{-} \\
& \mathrm{H}_{4} \mathrm{PO}_{4}^{+}+X^{-} \rightarrow \mathrm{H}_{3} \mathrm{PO}_{4}+\mathrm{H} X \uparrow
\end{aligned}
$$

where $X=\mathrm{Cl}$ or OEt. The Lewis acidity of a cholro group is higher than that of an ethoxy group. This is because the reactivity of the acid-base reaction is higher than that of the ethanol condensation reaction.

It is obvious from Table 2 and Fig. 3 that the softening temperature depends on the yields of the network formation reaction. This result is in agreement with the previous report on silicophosphate hybrids. ${ }^{13)}$

According to the quantum chemical calculations, the silicophenylphosphite hybrid was more durable than the silicophosphate hybrid because the hydrolysis activation energy was $1.9 \mathrm{~kJ} / \mathrm{mol}$ in model I, while the relative energy increased monotonously in model II. Indeed, the oxygen charge on the Si-O-P bonding in model II is less than in model I due to the electrophobic phenyl group on $\mathrm{P}$; this resulted in the suppression of the hydrolysis of Si-O-P bond. Additionally, the steric hindrance of the phenyl group improves the durability of the hybrids. The water durability observed, as shown in Fig. 3, agreed with that obtained by using the quantum chemical calculations: silicophenylphosphite hybrid (sample C) was more durable than silicophosphate hybrid (sample A).

The samples prepared by using diphenyldichlorosilane were less durable than those prepared by using diphenyldiethoxysilane, although the yields of network formation were high in the 
former sample. We consider that the samples prepared by using diphenyldichlorosilane contained residual $\mathrm{HCl}$, which assisted the hydrolysis of the hybrids in the presence of the water. Indeed, the appearance of the less durable hybrids was more opaque. This indicates that the following hydrolysis and gelation occurred in the hybrids.

$$
\begin{aligned}
& \mathrm{Si}-\mathrm{O}-\mathrm{P}+\mathrm{H}_{2} \mathrm{O} \rightarrow \mathrm{SiOH}+\mathrm{POH} \\
& 2 \mathrm{SiOH} \rightarrow \mathrm{Si}-\mathrm{O}-\mathrm{Si}+\mathrm{H}_{2} \mathrm{O}
\end{aligned}
$$

As described in NMR result section, the yield of the $\mathrm{Si}-\mathrm{O}-\mathrm{P}$ bonding in the samples prepared by using diphenyldiethoxysilane was low. Nevertheless, the durability of these samples was high, indicating that these materials can be used as highly durable low-melting hybrids for optical host application.

\section{Conclusions}

We developed new class of the organic-inorganic silicophosphate and silicophosphite hybrids via the solventless alcohol condensation under the catalyst-free, low-temperature, one-pot condition. This reaction provided crack-free monolithic materials easily because of no solvent evaporation. The hybrid material shows low-melting property, as melting temperatures ranged from 50 to $110^{\circ} \mathrm{C}$ where the organic dyes do not degrade. We also investigated the local structure using ${ }^{29} \mathrm{Si}$ and ${ }^{31} \mathrm{P}$ NMR. The reaction provided alternating polymerization, i.e. $\mathrm{Si}-\mathrm{O}-\mathrm{P}$ formation, for the most parts, although the self-condensation, i.e. $\mathrm{Si}-\mathrm{O}-\mathrm{Si}$ or $\mathrm{P}-\mathrm{O}-\mathrm{P}$ formation, occurred. The functional centers such as the rare earth ions will disperse homogeneously in the alternating copolymer of silicate and phosphate as reported previously. Additionally, the chemical durability was much higher than that of the hybrids prepared by the acid-base reaction. Therefore, the present hybrid material is a good candidate of the optical host material for the organic and/or inorganic functional centers.

The quantum chemical calculations were revealed that the improvement in water durability was due to the suppression of the hydrolysis of the $\mathrm{Si}-\mathrm{O}-\mathrm{P}$ bonding because the phenyl group on $\mathrm{P}$ decreases the oxygen charge on the $\mathrm{Si}-\mathrm{O}-\mathrm{P}$ bonding.

Acknowledgements This work was financially supported by the Grants-in-Aid for the Scientific Research from Japan Society for the Promotion of Science, No. 20613007. One of the authors (Y. T.) acknowledges the financial support from The Murata Science Foundation. The computation time was provided by the Supercomputer Laboratory, Institute for Chemical Research, Kyoto University.

\section{References}

1) C. Sanchez, B. Lebeau, F. Chaput and J.-P. Boilot, Adv. Mater.,
15, 1969-1994 (2003)

2) C. J. Brinker and G. W. Scherer, "Sol-Gel Science," Academic Press (1990).

3) H. Niida, M. Takahashi, T. Uchino and T. Yoko, J. Mater. Res., 18, 1081-1086 (2003).

4) H. Niida, M. Takahashi, T. Uchino and T. Yoko, J. Ceram. Soc. Japan, 111, 171-175 (2003).

5) M. Takahashi, H. Niida, Y. Tokuda and T. Yoko, J. Non-Cryst. Solids, 326\&327, 524-528 (2003).

6) H. Niida, M. Takahashi, T. Uchino and T. Yoko, J. Non-Cryst. Solids, 306, 292-299 (2002).

7) H. Niida, Y. Tokuda, M. Takahashi, T. Uchino and T. Yoko, J. Non-Cryst. Solids, 311, 145-153 (2002).

8) H. Niida, M. Takahashi, T. Uchino and T. Yoko, J. Mater. Res., 18, 1-3 (2003).

9) M. Takahashi, M. Saito, M. Mizuno, H. Kakiuchida, Y. Tokuda and T. Yoko, Appl. Phys. Lett., 88, 191914 (2006).

10) B. Menaa, H. Masai, M. Takahashi, Y. Tokuda and T. Yoko, J. Solid State Chem., 176, 493-500 (2006).

11) M. Mizuno, M. Takahashi, Y. Tokuda and T. Yoko, Chem. Mat., 18, 2075-2080 (2006)

12) M. Mizuno, M. Takahashi, Y. Tokuda and T. Yoko, J. Sol-Gel Sci. Tech., 44, 47-52 (2007).

13) M. Mizuno, M. Takahashi and T. Yoko, J. Mater. Res., 21, 1798-1806 (2006).

14) A. Vioux, Chem. Mater., 9, 2292 (1997).

15) C. F. Lorenzo, L. Esquivias, P. Barboux, J. Maquet and F. Taulelle, J. Non-Cryst. Solids, 176, 189 (1994).

16) Gaussian 03, Revision C.02, M. J. Frisch, G. W. Trucks, H. B. Schlegel, G. E. Scuseria, M. A. Robb, J. R. Cheeseman, J. A. Montgomery, Jr., T. Vreven, K. N. Kudin, J. C. Burant, J. M. Millam, S. S. Iyengar, J. Tomasi, V. Barone, B. Mennucci, M. Cossi, G. Scalmani, N. Rega, G. A. Petersson, H. Nakatsuji, M. Hada, M. Ehara, K. Toyota, R. Fukuda, J. Hasegawa, M. Ishida, T. Nakajima, Y. Honda, O. Kitao, H. Nakai, M. Klene, X. Li, J. E. Knox, H. P. Hratchian, J. B. Cross, V. Bakken, C. Adamo, J. Jaramillo, R. Gomperts, R. E. Stratmann, O. Yazyev, A. J. Austin, R. Cammi, C. Pomelli, J. W. Ochterski, P. Y. Ayala, K. Morokuma, G. A. Voth, P. Salvador, J. J. Dannenberg, V. G. Zakrzewski, S. Dapprich, A. D. Daniels, M. C. Strain, O. Farkas, D. K. Malick, A. D. Rabuck, K. Raghavachari, J. B. Foresman, J. V. Ortiz, Q. Cui, A. G. Baboul, S. Clifford, J. Cioslowski, B. B. Stefanov, G. Liu, A. Liashenko, P. Piskorz, I. Komaromi, R. L. Martin, D. J. Fox, T. Keith, M. A. Al-Laham, C. Y. Peng, A. Nanayakkara, M. Challacombe, P. M. W. Gill, B. Johnson, W. Chen, M. W. Wong, C. Gonzalez, and J. A. Pople, Gaussian, Inc., Wallingford CT, 2004.

17) M. Smaihi, T. Jermoumi and Marignan, J. Chem. Mater., 7, 2293 (1995)

18) H. Masai, M. Takahashi, Y. Tokuda and T. Yoko, J. Ceram. Soc. Japan, 113, 259-262 (2005) 